\title{
Exploration and Thinking on the Application of Interactive Educational Theory in College English Teaching in Multimedia Environment
}

\author{
Zujun Chen \\ Xi'an Peihua University, Xi'an, 710100, China
}

\begin{abstract}
With the reform and development of education model, multimedia teaching has been widely used, changing the traditional classroom environment. The concept of interactive teaching is a kind of teaching idea that arises in the multimedia teaching environment. In the multimedia environment, the interactive teaching of college Englishcultivates the interest of students, improves the teaching efficiency and introduces the Anglo-American culture in classroom. Interactive teaching has gradually become the mainstream teaching method of college English in the multimedia environment.

Keywords:interactive educational theory, interactive teaching, multimedia, college English

\section{Introduction}

The emergence of Interactive English teaching method not only has the basis of linguistics and psychology, but also meets the practical needs of English teaching reform. At present, the teaching method itself has the advantage, the passive situation of university students' English learning to change greatly, enhance their initiative and enthusiasm in learning English, but also more effectively cultivate their English learning ability, language ability and communicative ability. Therefore, more and more college English teachers pay more attention to the interactive teaching method. With the development and progress of science and technology, the mode of education has changed greatly. The exploration of English Teaching in the multimedia environment in colleges and universities in China, our shortcomings in the traditional teaching model, improving the
\end{abstract}


relationship between teachers and students, reflect the subject position of students, improve the learning efficiency and learning consciousness of students. The application of interactive teaching concept in multimedia environment is the development direction of college English Teaching in our country.

\section{Basic models of interactive teaching}

\subsection{Brain storm}

In the classroom, in order to make students concentrate on learning English is encouraged and confident. We can also use brainstorming form: the teacher put a question or statement of a topic. To determine a good time limit, let each student to speak freely, not anyone else's point of view to make any comment, so that we can speak freely the view. When the student's learning state is active, the teacher to the students just to give feedback, and simple summary. Teachers do not determine the standard point of view, as long as it does not touch the bottom line, reservations about the views of all parties. Practice has proved that this activity is conducive to strengthening the interaction between teachers and students, so that students are willing to actively participate in the classroom, and effectively improve their oral expression ability and speculative ability. When a group of people generate new ideas, this situation is called brainstorming. As team discussions use unconstrained rules, people are able to think more freely into new areas of thought, creating many new ideas and solutions. When participants have new ideas and ideas, they say it out loud, and then set up new ideas on other people's ideas. These ideas and ideas are evaluated at the end of brainstorming sessions. Brainstorming is a way to develop creative thinking, which is good for students' thinking ability.

\subsection{Group discussion}

This model emphasizes the creation of real situation, through the multimedia teaching equipment will be teaching content in the stories show on the screen, the visual and image enhancement teaching, stimulate students' learning interest and enthusiasm. In the form of group discussion, each student can integrate into the classroom. In the discussion of the topic, it can not only improve the students' language ability, but also cultivate students' cooperative spirit. Through the coordination and organization of the team leader, each participant can express their views, listen to the views of others, and actively communicate with teachers to build personal knowledge structure. The teacher will give each group a small group leader, clear the task of each member, including the collection of information, comprehensive discussion, analysis of data, to complete the preparatory work. In the discussion, guidance and supervision of teachers is very important, to ensure that each team member is discussed to speak in English, enthusiasm is not strong in the class to give great encouragement good at giving systematic guidance. At the same time, teachers should also guide students to use some of the commonly used phrases and expressions. Finally, the English teacher 
will answer all the questions in order to guide the students to learn the contents of the text will have a correct understanding. The purpose of this activity is to stimulate students' interest in the topic of the text, and to think about it. It can cultivate students' ability to summarize the answers and improve their oral expression ability.

\subsection{Role playing}

The purpose of learning English for students is to use it in different situations and work in the future. Therefore, in College English class, we should design a variety of simulation situations, to provide students with a good environment for the application of English knowledge, and exercise their ability to perform and speak. The common role includes performing English movie clips, the novel style adapted into English performing simulated interview etc.: due to the high requirement for the activities of the students English comprehensive application ability, can put the students in small groups. Each group is free to choose what they want to perform. In the course of the class, it is well prepared by the way of group work.Each team should tell the teacher the performance in advance. Arrange a group for ten minutes before each class. There is a lot of room for innovation in this role-playing interaction. Role play can also be designed to improvise. Students are then given an impromptu interview or debate. The activity will give the students a deep impression to improve their oral expression ability and performance ability. It needs cooperation between students in the preparation and performance of the event. This can greatly improve the students' cooperative learning ability, but also enhance the friendship, loved by the students.

\section{Important functions of multimedia in the interactive teaching of college English}

\subsection{Cultivate student's interest}

It can provide rich learning materials in the application of multimedia teaching equipment for interactive English teaching, so that students are faced with colorful pictures and vivid sound, rather than monotonous writing on the blackboard. It will make the classroom become rich and vivid, expressive forms. Under the premise of the equipment and the teachers and so on, it is suggested that the multimedia teaching should adopt the small class teaching mode, so that every student has the opportunity to participate in the classroom activities. At the same time, teachers should pay attention to and encourage students to participate in classroom activities. Only in this way can we develop the students' subjective initiative and reflect the advantages of multimedia teaching as an important supplementary means of modern foreign language teaching. Teachers affirm their imagination and creativity as a means to stimulate their active learning. In the actual teaching process, it is not necessary for the teachers to click the contents of the courseware, because it will not only make students feel tired, but also a waste 
of time. The contents of these writers are, just as a reference for teachers in class, teachers can make appropriate modifications according to the actual contents of the textbooks, students can make use of the potential of imagination and insight, enrich classroom content, active classroom atmosphere. Teachers should use various methods to stimulate students' autonomy and initiative, so as to achieve the desired effect.

\subsection{Enhance class efficiency}

In the multimedia environment, teachers can take more time and effort to communicate with the students, the classroom interaction control, understand the individual differences of students and student interest in learning, discussed in the warm atmosphere in the classroom, enable students to deepen their understanding of knowledge and memory, strengthen the use of English language, improve students' learning efficiency. The concentration of teachers' lectures saves the teaching time, increases the amount of teaching and improves the teaching efficiency. Before each lesson the teacher writing on the blackboard and explain to the class for a lot of time, teaching information is limited by the amount of. The use of multimedia, classroom teachers to teach the content in advance has been compiled in the courseware, eliminates many useless labor and students to take notes in teaching. Through the text and voice input to students, both vivid image, but also save a lot of classroom time, can increase the unit time of teaching information, but also can be used to allow students to practice and practice, in order to deepen the memory. In addition, a series of teaching links are realized by computer, which reduces the burden of teachers. When you teach a word, you can use the multimedia projection on the big screen. The teacher opened the broadcast system audio tape, supplemented by sentence translation. The new words are strengthened in pronunciation, intonation spelling, interpretation, application and so on. Modern information technology, such as email, audio, video and data, facilitates the interaction between teachers and students. One stop teaching improves the efficiency of classroom teaching.

\subsection{Introduce English culture}

Language and culture are interdependent. The mastery of background and cultural knowledge plays an important role in English reading. The use of multimedia technology to play some of the teaching content related to audiovisual materials or presentation, so that students on the scene, the invisible grasp and understanding of the English speaking countries of social and cultural practices. In the increasingly frequent economic and cultural exchanges, the primary task of college English teaching is to improve the students' ability to control the language and enhance their ability of cross-cultural communication. Every text in college English textbooks are related to a cultural or social aspect, the purpose is to create a by point and the fluctuation effect, make the students as a starting point, a profound understanding of the cultural and social phenomenon behind. The teacher can make full use of multimedia network such a large information base, guide students to search for relevant background information, 
broaden the growth of knowledge, and then to oral presentation in class with other students sharing. This can not only promote the initiative of students' autonomous learning, but also can improve the students' ability to control the spoken language. The harmonious relationship between teachers and students is the basis of classroom interaction. Teachers can create a variety of ways to interact with teachers and students in the scene, such as the role of the story can be driven by the interaction between teachers and students. In the interaction between teachers and students, it can enhance the understanding of British and American culture.

\section{Conclusion}

The application of interactive teaching method in college English teaching is an innovation of traditional teaching methods. It not only explores the potential and ability of teachers and students, but also meets the practical needs of English teaching reform.Nowadays, with the development of multimedia, interactive teaching theory will play a more important role in college English teaching.

\section{References}

[1] Li Tan, A Study on the College English Listening\&Reading under theTheory of Multi-interaction in the Media Communication Era, Journal of Hunan Industry Polytechnic, 16(2), pp. 82-84, 2016.

[2]Deng Lianmei, On the Application of Interactive Educational Theory in College Public English Teaching via Multi-media, Journal of Mianyang Normal University, 32(9), pp. 131-134, 2013.

[3]Cai Yan, Jiang Mingjuan, College English interactive teaching based on network technology, Journal of Jiamusi Vocational Institute, 32(10), pp. 395-396, 2015.

[4]Kong Xiangna, Apply the Interactive Method of Teaching to College English Teaching, Academic Journal of Shanxi Provincial Committee Party School of C.P.C, 34(3), pp. 126-128, 2011. 